\title{
DISPOSITIVOS IMPLEMENTADOS PELO SERVIÇO AEROMÉDICO UAPISESA PR BASE CASCAVEL EM PROL DA HUMANIZAÇÃO NOS ATENDIMENTOS NEONATAIS
}

\author{
Vanessa COLDEBELLA ${ }^{1}$; Liandra Kasparowiz GRANDO²
}

\section{RESUMO}

O Ministério da Saúde, em 2003, intitulou a Política Nacional de Humanização, regida pelos princípios do Sistema Único de Saúde. Nos serviços que prestam assistência de urgências e emergências é notado que a tecnologia pode distanciar o cuidador da humanização. É neste contexto que se enquadra o suporte avançado aeromédico, consolidado no Estado do Paraná através da UAP (Unidade Aérea Pública) que conta com 5 bases. No intuito de trazer a humanização para os recém-nascidos (RNs) atendidos, a equipe aeromédica da base Cascavel implementou medidas que impactaram na qualidade assistencial e conforto desses pequenos pacientes, sendo o objetivo desse estudo descrever e justificar cada uma dessas medidas. Constitui-se um estudo de abordagem descritiva e exploratória. Primeiramente, desenvolveu-se um instrumento de checklist neonatal, colaborando com a qualidade das informações coletadas pela central de regulação, auxiliando no gerenciamento e execução dos procedimentos. Como segunda medida, identificou-se, por experiência, que o maior benefício para o RN é alcançado quando se realiza o transporte leito a leito, pois permite a estabilização e manipulação em ambiente controlado. Para isso, o uso do dispositivo Baby Pod II se mostrou o mais indicado para ser deslocado até as unidades de saúde. Para completar esse grupo de cuidados foi implantado o projeto Aeropolvo, com objetivo de proteger e amenizar os estressores de voo e o abafador auricular para a preservação auditiva dos neonatos transportados. Entende-se que a gravidade e fragilidade dos RNs atendidos torna a humanização imprescindível para acolher e minimizar todo o desgaste envolvido no transporte e internação.

PALAVRAS-CHAVE: humanização da assistência, neonatologia, resgate aéreo.

\section{INTRODUÇÃO}

Em 2000, o Ministério da Saúde, regulamentou o Programa Nacional de Humanização da Assistência Hospitalar. Visando abranger todos os níveis de atenção à saúde, em 2003, considerou a humanização não apenas como um programa, mas a intitulou Política Nacional de Humanização $(\mathrm{PNH})$, regida pelos princípios do Sistema Único de Saúde (BRASIL, 2003).

Nos serviços que prestam assistência a pacientes criticamente enfermos, graves ou potencialmente graves, o impacto da tecnologia é observado para o

\footnotetext{
1 Enfermeira especialista em Medicina Aeroespacial e Transporte Aeromédico /Enfermeira assistencial do serviço aeromédico base Cascavel/PR. vanessacolde@gmail.com

2Enfermeira especialista em Medicina Aeroespacial e Transporte Aeromédico /Enfermeira assistencial do serviço aeromédico base Cascavel/PR. liandrakg@gmail.com
} 


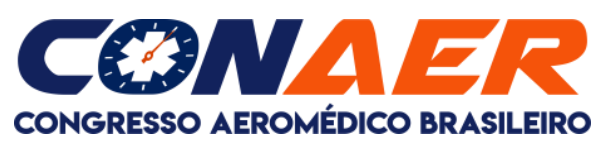

tratamento e manutenção da vida, e esses meios podem distanciar o cuidador da humanização. Assim, nesses ambientes, é preciso refletir sobre o sentido real da assistência, partindo do pressuposto de que o usuário tem o direito de satisfação com o serviço por meio de um cuidado humano com qualidade (CHERNICHARO et al, 2011). É neste contexto de atendimento às urgências e emergências, cercado de tecnologia, que se enquadra o suporte avançado aeromédico consolidado no Estado do Paraná através da UAP (Unidade Aérea Pública), que conta com 5 bases ( 5 asas rotativas e 01 asa fixa) com a cobertura de todo o Estado. $O$ atendimento aeromédico visa chegar o mais precocemente ao paciente (do neonato a terceira idade) após o agravo a saúde que possa levar a sequelas e/ou morte, prestando um atendimento qualificado e ágil da origem ao destino.

No intuito de trazer a humanização para os recém-nascidos (RNs) atendidos, a equipe aeromédica do oeste do Paraná/base Cascavel implementou algumas medidas que impactaram diretamente na qualidade da assistência e no conforto desses pequenos pacientes, como: 1) Desenvolvimento de instrumento checklist para a coleta de dados das missões neonatais; 2) Uso do dispositivo de transporte portátil Baby Pod II para a realização dos atendimentos neonatais leito a leito; 3) Implantação do projeto Aeropolvo, adaptando uma iniciativa a princípio desenvolvida somente em UTIs (Unidades de Terapia Intensiva) para a realidade do aeromédico e; 4) Utilização do abafador auricular neonatal para a proteção auditiva dos neonatos transportados.

Sendo o objetivo desse estudo descrever e justificar cada uma dessæmedidas implementadas no serviço.

\section{METODOLOGIA}

Constitui-se um estudo de abordagem descritiva e exploratória, que apresenta um instrumento próprio de checagem desenvolvido pela equipe (checklist neonatal), o registro dos benefícios das tecnologias utilizadas nos atendimentos neonatais (dispositivo de transporte e abafador auricular), bem como a fundamentação, execução e avaliação do projeto Aeropolvo implantado no serviço. O presente estudo é a descrição de todos os procedimentos aplicados no atendimento neonatal do Serviço de transporte aeromédico base de Cascavel/PR.

\section{RESULTADOS E DISCUSSÃO}

Para a triagem dos acionamentos aeromédicos neonatais, viu-se a necessidade de elaborar um instrumento próprio de verificação de dados (checklist) 


\section{CON

para colaborar com a coleta das informações pela central de regulação. O checklist é definido como uma ferramenta estruturada de comunicação, que inspirada na aviação, fragmenta tarefas complexas diminuindo as chances de esquecimento de algum item fundamental (OMS, 2009). Agrupou-se nessa lista sinais vitais, diagnóstico, suporte ventilatório, acesso venoso e sondagens, incluindo itens relevantes à neonatalogia como: dia e hora do nascimento, APGAR, idade gestacional, peso e bolsa rota materna. Como benefício da implantação do checklist na regulação teve-se o ganho evidente na qualidade das informações coletadas, o que colaborou diretamente no gerenciamento, organização e execução dos procedimentos prestados, visando a segurança e a qualidade da assistência.

Na experiência dos transportes neonatais já realizados pela base (mais de 360 neonatos) identificou-se que o maior benefício para o RN é alcançado quando se realiza o transporte leito a leito, pois permite a estabilização e manipulação do mesmo em ambiente controlado, evitando a exposição do RN em áreas de pouso (pista) com risco de desestabilização e hipotermia. Para a realização desse transporte leito a leito a utilização do dispositivo Baby Pod II se mostra o mais indicado, já que possui a vantagem de ser leve, portátil e se ajustar perfeitamente sobre a maca da aeronave, juntamente com os outros equipamentos para ser deslocado até as unidades de saúde da origem e destino. Este dispositivo consiste em um invólucro ultraleve em fibra de carbono (mesmo material utilizado nos carros de Fórmula 1), tampas transparentes (facilitando a visão do RN), com forro interno de espuma (absorção de impacto e vibração), bem como fitas de segurança para fixar o paciente dentro do dispositivo (BABY POD II, 2003). Para o seu aquecimento conta com colchão térmico ativado quimicamente de acordo com a temperatura ambiente, peso, idade gestacional e temperatura do RN na origem.

Com o objetivo de trazer mais conforto e humanização foi desenvolvido o projeto Aeropolvo, com o intuito de diminuir o stress dos RNs transportados, evitando complicações como a perda de peso e alterações hemodinâmicas, amenizando os estressores de voo (turbulência, ruídos, vibrações) e ainda evitando que os bebês puxem dispositivos instalados como a sonda e tubos orotraqueais. O Projeto Octo Polvo Terapêutico foi criado na Dinamarca em 2013 para ajudar bebês recémnascidos prematuramente a se sentirem mais seguros e confortáveis nas incubadoras no ambiente hospitalar, dando aos RNs um polvinho de crochê em fios $100 \%$ algodão 


\section{CON \\ CONGRESSO AEROMÉDICO BRASILEIRO}

com 8 tentáculos de 22cm de comprimento. Segundo o estudo, os tentáculos do polvo assemelham-se ao cordão umbilical e reproduzem, de certa forma, o ambiente no interior do útero da mãe trazendo segurança e ainda evitando acidentes e choques nas paredes da incubadora (THE DANISH OCTO PROJECT, 2017).

Por fim, com o emprego do abafador auricular neonatal, que proporciona a redução de ruído em até $30 \mathrm{~dB}$, constituído por um par de conchas acústicas acolchoadas e macias que são ajustadas suavemente por uma faixa de cabeça, conseguiu-se trazer a bordo a proteção auditiva que tanto preocupava a equipe por se tratar de transporte em asas rotativas (MAGALHÃES, 2016).

\section{CONSIDERAÇÕES FINAIS}

Levando-se em consideração o ambiente aeromédico com tantos estressores envolvidos, somado a gravidade e fragilidade dos recém-nascidos atendidos, entendese que a humanização no atendimento se torna imprescindível, implicando na articulação dos avanços tecnológicos e ampliação do processo comunicacional para o desenvolvimento de uma assistência singular, que proporcione uma visão holística do RN, buscando com isso acolher e minimizar todo o desgaste humano e familiar relacionado ao período do transporte e internação.

\section{REFERÊNCIAS}

1. BABY POD II. Manual de uso y mantenimiento. Revisión 5, 01/11 del Manual de Operador de Baby Pod II, presentado en Diciembre de 2003. 2003-2011 • Advanced Healthcare Technology Ltd. • Baby Pod II. www.babypod.

2. BRASIL. Ministério da Saúde. Secretaria de Atenção à Saúde. Política Nacional de Humanização - PNH. Brasília: Ministério da Saúde; 2013.

3. CHERNICHARO, Isis de Moraes et al. Humanização no cuidado de enfermagem nas concepções de profissionais de enfermagem. Esc Anna Nery Rev Enferm. 2011;15(4):686-93.

4. MAGALHÃES, Gladys. Como proteger as crianças em locais muito barulhentos. Crescer, 2016. Disponível em http://revistacrescer.globo.com/, acesso em 22 de julho de 2021.

5. OMS. Organização Mundial da Saúde. Segundo desafio global para a segurança do paciente: Cirurgias seguras salvam vidas (orientações para cirurgia segura da OMS). Rio de Janeiro. Organização Pan-Americana da Saúde. Ministério da Saúde. Agência Nacional de Vigilância Sanitária, 2009.

6.THE DANISH OCTO PROJECT. Disponível em: https://www.spruttegruppen.dk/danish-octo-project-english/>. Consultado em 07 de jul/2019. Um Polvo de Amor: saiba tudo sobre essa iniciativa. ONG Prematuridade.com. 